\title{
An Investigation of Relevance from Curriculum-Aligned Making in the Elementary School Science Classroom
}

\section{Full Paper}

\author{
Sharon Lynn Chu \\ The Embodied Learning \& Experience \\ (ELX) Lab \\ University of Florida \\ slchu@ufl.edu
}

\author{
Brittany Garcia \\ The Embodied Learning \& Experience \\ (ELX) Lab \\ University of Florida \\ b.garcia@ufl.edu
}

\author{
Elizabeth Deuermeyer \\ Texas Institute for \\ Technology-Infused Learning \\ Texas AM University \\ e.deuermeyer@tamu.edu
}

\author{
Skylar Deady \\ Texas Institute for \\ Technology-Infused Learning \\ Texas AM University \\ skylardeady@tamu.edu
}

Francis Quek

Texas Institute for

Technology-Infused Learning

Texas AM University

quek@tamu.edu

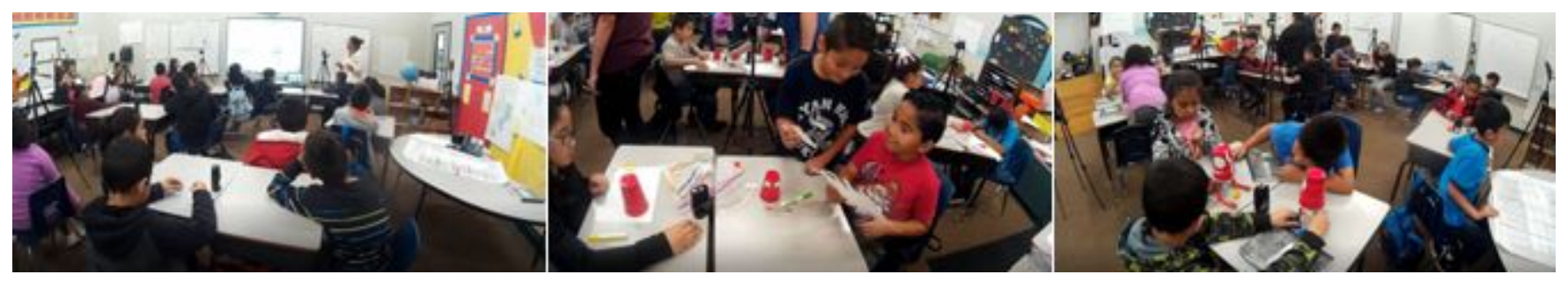

Figure 1: Elementary school children engaging in Making during science lessons

\begin{abstract}
Little research addresses Making as an approach that may impact the relevance of science to students. This paper investigates whether and how students make connections to their everyday life during curriculum-aligned Making activities. We argue that Making, with its focus on hands-on construction and technology, can act a possible bridge between 'school science', which tends to focus on formal models of science concepts, and 'everyday science', that addresses directly
\end{abstract}

Permission to make digital or hard copies of all or part of this work for personal or classroom use is granted without fee provided that copies are not made or distributed for profit or commercial advantage and that copies bear this notice and the full citation on the first page. Copyrights for components of this work owned by others than the author(s) must be honored. Abstracting with credit is permitted. To copy otherwise, or republish, to post on servers or to redistribute to lists, requires prior specific permission and/or a fee. Request permissions from permissions@acm.org. FabLearn'19, March 2019, NY,NY USA

(C) 2019 Copyright held by the owner/author(s). Publication rights licensed to ACM.

ACM ISBN 123-4567-24-567/08/06 ..\$15.00

DOI: $10.1145 / 3311890.3311891$ the application of science concepts. We analyzed videos from an ongoing longitudinal Maker program where Making is integrated into third-, fourth-, and fifth-grade classes at public elementary and intermediate schools. Our qualitative analysis revealed eight different ways in which elementary students found relevance in curriculum-aligned science Making activities. The most frequent types of 'relevance' were the use of analogies and the application of everyday knowledge to aspects of the Making activity. In the Making activities, students drew relevance with six aspects of Making. The Making product or physical design triggered relevance connections most often. We conclude that despite its focus on learning objectives of formal science curricula, curriculum-aligned Making allows students to make connections with their everyday life, and may potentially be used as an approach to make school science more personally relevant for students.

\section{CCS CONCEPTS}

- Human-centered computing $\rightarrow$ HCI theory, concepts and models; 


\section{KEYWORDS}

Making; Learning; Curriculum; Elementary Education; Science; Relevance

\section{ACM Reference Format:}

Sharon Lynn Chu, Brittany Garcia, Elizabeth Deuermeyer, Skylar Deady, and Francis Quek. 2019. An Investigation of Relevance from Curriculum-Aligned Making in the Elementary School Science Classroom: Full Paper. In Proceedings of ACM FabLearn NYC Conference (FabLearn'19). ACM, New York, NY, USA, 9 pages. https: //doi.org/10.475/123_4

\section{INTRODUCTION}

This paper investigates how Making may help to make learning relevant to students when used in elementary school science classrooms. Much research has shown that students need to perceive content to be useful or relevant to themselves for them to be interested, engaged and motivated in the subject matter. However, despite the myriad of investigations on how to improve science instruction (e.g., $[1,6,14,19])$, students in current science classes still have a difficult time seeing the relevance of topics learned in class to their everyday life. A primary reason for this lack of relevance is that science in the classroom is often still taught in a manner that has been termed 'school science'. School science typically focuses on explaining models of how scientific processes work, and can be contrasted to 'everyday science', which is concerned with how science can be applied to everyday scenarios. School science has been shown to result in students having difficulty with finding taught topics relevant [7].

Making as an approach to science instruction not only encompasses a set of flexible and accessible technologies, but also instills a set of principles centered around hands-on construction of artifacts. With its practical focus, Making may thus be a fitting means to link school science and everyday science. This proposition that we make emerges from our experiences conducting Making-based science lessons with third-, fourth- and fifth-grade public elementary school students over a period of more than three years. In this paper, we use a qualitative approach to analyze at a micro level how students engaged in Making connected school science to everyday scenarios with little to no prompting. We found six main ways by which Making evokes relevance during science learning.

Following, we first contextualize our work by describing the type of Making that we address, and prior related work that has provided indications of the usefulness of Making to impact content relevance in learning. We then present a theoretical foundation for why Making may be able to create an environment and a frame of mind in which students are better able to connect school science with their everyday lives. We next describe our dataset, analysis method, and findings, and wrap up with a discussion of the potential of
Making to transform science learning in the classroom to be more relevant for students.

\section{BACKGROUND: CURRICULUM-ALIGNED MAKING}

Making typically refers to the practices surrounding the use of a set of technologies that include electronics, 3D printing, programming and microprocessors, as despecialized means of prototyping and creating technology-based artifacts. As a broad movement, the Maker movement has often been linked to hacking and the hacker culture. However, how Making may be implemented in pragmatic learning situations is still in question. The implementation of Making in educationally-oriented scenarios has distinctive features compared to informal or community Makerspaces. There is thus an important need to first clarify the kind of Making that we address in our research.

In this paper, we explore mainly curriculum-aligned Making. Curriculum-aligned Making involves Making activities that are matched to or aligned with specific learning standards as described in formal school curricula for specific subject matters [8]. This type of Making is particularly applicable for formal educational contexts, since these have the additional constraint of satisfying learning objectives, while ensuring that the creative, project- and discovery-based spirit embodied in the Maker movement is maintained. Fulfilling both Making and learning goals simultaneously is very challenging because Making and formal education tend to have conflicting methods and standards. For example, while Making emphasizes and values discovery and innovation, modern public school systems are driven by scheduled lesson plans and accountability [13]. Conversely, rigid learning objectives are not typically a major focus in informal Makerspaces.

We highlight two key distinctions of curriculum-aligned Making when compared to other conceptualizations of Making as applied to learning in the literature.

Clapp et al. [9] used the term Maker-Centered Learning. They define Maker-centered learning through three constellations of characteristics: a. characteristics related to community (collaboration, sharing, diverse skills); b. characteristics related to process (curiosity-driven, experimental learning, prototyping, interdisciplinary problem-solving); and c. characteristics related to environment (3D printers, etc.). Many projects in Maker-centered learning appear to follow one model whereby students are made to engage in projects in which they build artifacts to solve real-world community or personal problems, or some other practical problems. The FabLab@School projects [5] are a good example of this model. For example, Dlodlo and Beyers [11] describe a fab lab project where South African girls were tasked to design a desk tidy for pencils and erasers. Togou et al. [20] relate a fab lab project in science classes in Ireland where students 
were made to design different kind of vases. Conversely, curriculum-aligned Making do not necessarily seek external problems to solve. The problems to be solved are the subject matter learning objectives themselves. Students build artifacts to directly support their learning of specific, for example, science standards in a science class.

A second key distinction is that curriculum-aligned Making does not necessarily involve open-ended exploration at all times. Open-ended exploration is more typical of Making projects that adopt a design perspective. Students engage in the design phase of iterative prototyping in Making projects, for instance in [2, 17]. In curriculumaligned Making, the tensions between Making philosophy and conventional school environments (testing, discipline, regimented schedules, large classroom size) are such that it is necessary to implement Making in a more guided, stepwise fashion. Even though some has described this approach as "step-by-step, recipe-like, construction activities" [21], it makes the integration of Making into school curricula more acceptable to school administrators and attenuate anxiety in teachers.

Cohen et al. [10] proposed a framework of Making in educational frameworks that may be useful to situate precisely curriculum-aligned Making. The framework specifies four ways to integrate Making in learning that are characterized by two dimensions (deliberate learning goals Vs playful/serendipitous learning goals; private process Vs shared/ collaborative process): 1. Art and design activities: Activities are formally integrated to support content at the end of a project; 2. Craft activities: Activities are informally integrated to support playful creativity; 3. Makified activities: Activities are formally integrated to support content throughout the entire project; and 4. Maker activities: Activities are informally integrated to support playful exploration. Curriculumaligned Making is situated within the space of makified activities.

\section{RELATED WORK: RELEVANCE FROM MAKING}

In Making for learning that directly addresses community or personal problem-solving, the aspect of relevance is embedded in the goals of the activity itself, much like in informal Makerspaces (e.g., afterschool Maker clubs). Curriculumaligned Making, on the other hand, maintains focus on the content learning objectives. Curriculum-aligned Making has thus been shown to positively impact not only students' interest in Making, but also students' interest and self-efficacy in the subject domain [8]. However, whether and how the Making activity help students to find relevance in the topic is not as evident.

The issue of Making, learning, and relevance has not been specifically studied in prior work. There are small indications of the potential of Making to increase relevance of the subject matter in studies investigating at a finer grain how children actually engage in Making activities. Bevan et al. [4] developed a framework of learning dimensions for tinkering activities through conversations among a team of researchers and practitioners. One of their learning dimensions is the 'development of understanding', of which an indicator is 'applying knowledge'. Applying knowledge is described as learners connecting to prior knowledge, including STEM (Science, Technology, Engineering, Mathematics) concepts. This dimension of learning conceptualizes relevance of content as students being able to see how the content relates to what they have previously learned either in previous lessons or from outside activities. Bevan et al. provide discourse excerpts from video analysis of visitors tinkering in a museum setting to illustrate how the learning dimension is seen in actual behaviors.

Subsequently commenting on the promise of Making in science education in a different article, Bevan [3] emphasized how Making can help to leverage learners' cultural resources: Making allows for the "blending of the everyday with the scientific, and...embeds STEM concepts in socially rich discourse and practices". To support this claim, she referenced work like Peppler's [16] that showed that Making activities relating to e-textiles tend to be more appealing for girls, and Fields and King [12] whose study with university students found that the students linked their coursework to "long-standing personal interests, bringing in skills and interests from everyday life" in a crafting class.

Somanath et al. [18] described a pilot project with 8 'atrisk' students aged 12 to 14 from an alternative school in Canada engaging in Maker projects using the LilyPad, Arduino and Makey-Makey. Students engaged in two tasks: a "real world task" (e.g., building a windshield wiper) and an "abstract concept task" (e.g., building a direction controller). The authors highlighted as their most important takeaway point that it is critical that students are able to see aspects of the activity that are relevant to them. Aspects of relevance could be in terms of "creative skills, problem solving skills or improving programming skills". At a more abstract level, relevance could be seen in "likability", "choice making", the student seeing "potential to further improve a particular skill set", and the student "envisioning future possibilities".

In summary, for Making activities whose goals are directly about projects that are personal to the students (e.g., an individual interest or a community problem), relevance is intrinsic and assumed. However, relevance is more problematic for Making activities that are more abstract in nature or aimed at a goal that is more foreign to students (e.g., science learning objectives). In the latter case, the literature seems to suggest that relevance during Making activities can be seen in the students being able to connect to their prior knowledge, bring in aspects of their cultural and everyday 
resources, resonate with the needed skills and inherent construction process, and see how facets of the project can be useful in the future.

\section{THEORETICAL FOUNDATION}

Why is it reasonable to expect that learning that includes Making activities would enable students to draw relevance between the science topic, the activity, and themselves? Research has shown that connecting school science with students' everyday experiences is actually very difficult for teachers [15]. Cajas [7] conjectured that this is because teachers either do not possess sufficient 'practical knowledge' or are not able to link their practical knowledge with school science that they are teaching.

As a potential approach to solve this problem, Cajas proposed the idea that "technology may be a key in connecting school science with everyday life" [7]. According to his proposition, technology and engineering require "a specific kind of knowledge developed by the demands of the specific design and the constraints of reality". For example, instead of focusing on the theory of heat transfer, a focus on technology would consider directly how a thermostat works.

We argue that Making precisely embodies Cajas' idea of technology as a link to relevant science for students. When Making is included in science learning, it shifts the focus of the learning to problem solving a technologically-oriented problem. This focus brings in turn aspects of hands-on construction, creativity and use of everyday materials into the learning of the science concepts. Our argument is illustrated very simply in Figure 2. Creating links between science concepts and aspects of everyday life (gray dashed line arrow) is challenging. However, the link to aspects of everyday life may be easier if the science concepts are encapsulated in a Making activity, as it is in curriculum-aligned Making. This link to aspects of everyday life is likely to make the science concepts more relevant for the students.

\section{STUDY}

\section{Research Questions}

Given our current lack of understanding of students' actual behaviors during Making activities, this research sought to answer the following specific questions:

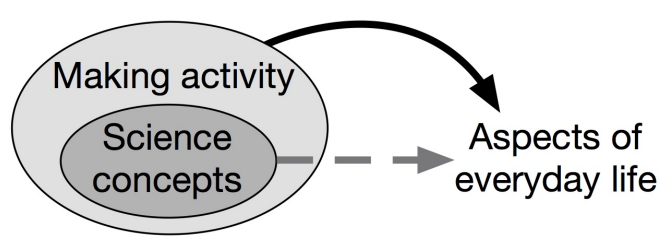

Figure 2: Theoretical framework
RQ1: Are students able to find aspects of relevance during curriculum-aligned Making activities?

RQ2: In what ways do students find relevance in curriculumaligned Making activities?

Answering these research questions will not only contribute to knowledge about behavioral themes during educative Making, but also how the design of curriculum-aligned Making activities can be improved so as to emphasize aspects that add to students' sense of relevance.

\section{Study Description}

We analyzed video data that was collected from a longitudinal program whereby Making was integrated into the science lessons of third-, fourth- and fifth-grade students (aged 8 to 11 years old) from one public elementary and one public intermediate school. The majority of the students in the schools were from underrepresented groups in STEM (72\% Latino, 26\% African American, 96\% on reduced lunch programs, $>50 \%$ Low-English Proficiency).

The Making activities were deployed during the formal science class for one week at a time (that we henceforth refer to as a 'Maker Week'). The school academic calendar in the district is such that each six-week period addresses one science topic. For a 36-week academic year, this totals up to six six-week periods or six science topics being addressed. We deployed one Maker week (4 days) for each science topic. Making activities were designed in consultation with the teachers, and each science lesson of the Maker week consisted of five main parts: i) initial instruction by the teacher; ii) Making instructions by a member of the design/research team; iii) students' engagement in Making; iv) conducting a science exercise with the artifacts made; v) post-exercise notetaking and discussion led by either the teacher or the researcher. Other than the guided instruction portions of the class, students were encouraged to work relatively autonomously and in free-flow interactions. The Making activities typically used technology such as basic electronics, $3 \mathrm{D}$ printing and fabrication, and computer programming. Two examples of the curriculum-aligned Making activities that the students engaged in are shown in Figures 3 and 4. Figure 1 shows screenshots from the videos of the science classroom of the students engaging in Making activities.

The Maker project has been ongoing for 3.5 years, with different third, fourth, and fifth-grade classes every year. All class sessions during all Maker weeks were audio- and videorecorded, with one camera and one audio recorder capturing each table of a maximum of four students in a classroom. The captured videos could thus provide us with a view of each student that was sufficiently close-up to determine what the student was doing with their hands. 


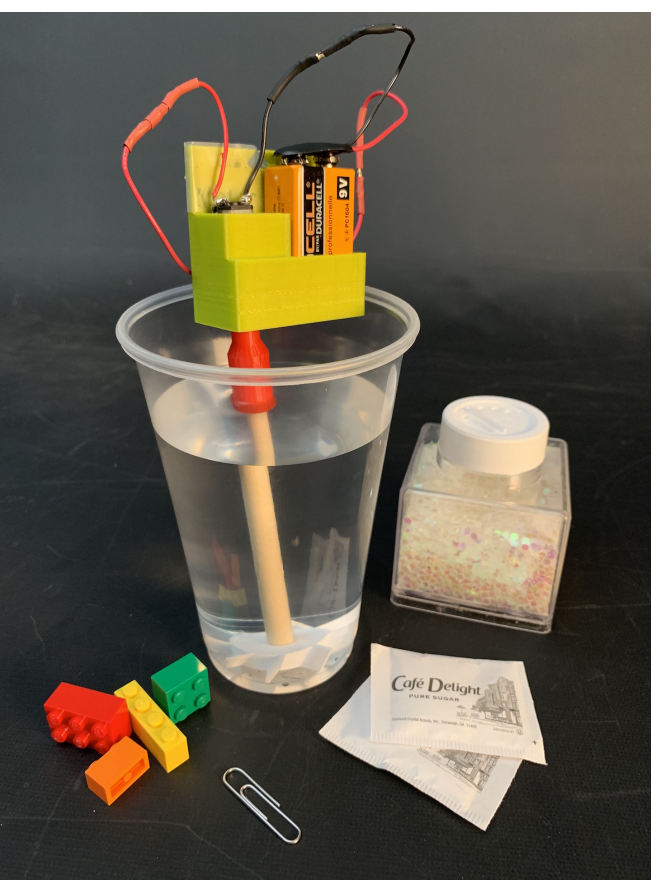

Figure 3: Materials for Mixture \& Solutions Maker activity

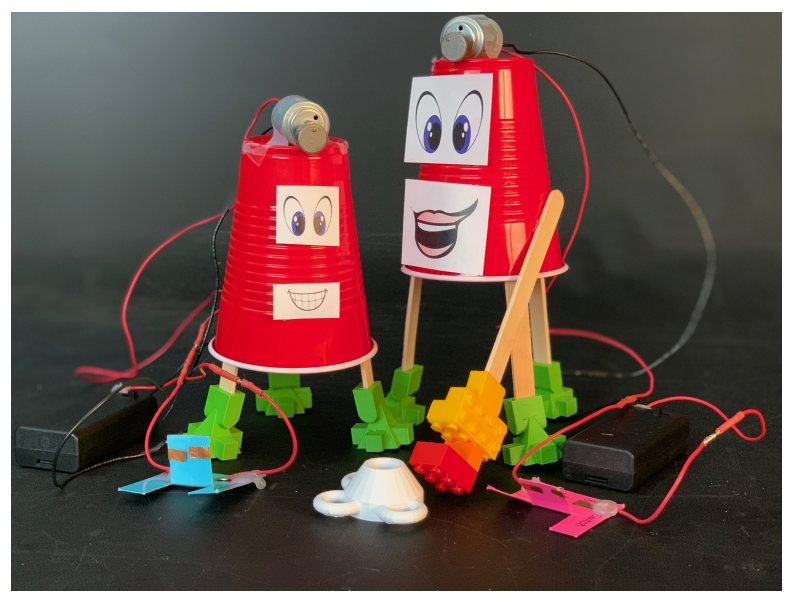

Figure 4: Materials for Adaptation Maker activity

\section{Dataset}

Over the course of 3.5 years, the Maker program has generated a massive amount of data. For this study, we randomly selected one Maker week from Year 2 of our program and one Maker week from Year 3. The Year 2 Maker week selected covered the science curriculum topic of Adaptation, and the Year 3 Maker week covered the topic of Mixtures and Solutions. The Making activities that were done for these two units are shown in Figures 3 and 4.
The learning goals that the Mixtures and Solutions Maker activity was aligned with were that students would be able to compare and contrast a variety of mixtures and solutions such as rocks in sand, sand in water, or sugar in water. On Day 1 of that Maker week, the students assembled a basic circuit with a motor. On Days 2 and 3, the students used what they learned the first day to power a 3D printed mixer head that is attached to a wooden dowel and rotating motor, and powered by a battery and circuit they built. With their homemade mixer, the students created various forms of mixtures and solutions to observe physical properties such as mass, magnetism, relative density, and solubility. On Day 4, the students continued to create various mixtures but also had to use a vibrating motor attached to a sifter to observe and test various methods for separating mixtures and solutions.

The learning goals that the Adaptation Maker activity was aligned with were that the students would understand that some characteristics of organisms are inherited such as the number of limbs on an animal or flower color, and recognize that some behaviors are learned in response to living in a certain environment such as animals using tools to get food. On Day 1, the students brainstormed traits that animal or human babies could inherit from parents as well as behaviors that could be learned, and the difference between the two. The students were then told that they would create a 'baby' robot that would 'inherit' traits from its 'parent' robot. Next, the students were introduced to an online 3D design tool called Tinkercad and were shown how to create various shapes using the program. On Day 2, the class worked together as a group to design 'feet' for their baby robot that they may inherit from the parent. On day 3 , the students used arts and craft materials to construct their baby robots while their 3D designed feet were being printed. And on day 4, the students assembled their baby robots with their 3D-printed feet, and were instructed that their robots would now 'learn' a new behavior: pushing a disc across the table. To do that, the students had to make their robots move and to design and construct a 'pusher' tool. Students assembled circuits with vibrating motors of various sizes on their robots, and built tools with Legos and 3D printed parts. If the tool did not successfully push the disc, students brainstormed with their group on how to improve the tool, and would then re-design their tool before attaching it to the robot to try again. In order to make their robots dance, students assembled circuits with vibrating motors of various sizes on their robots. Groups took turns using the motors to 'teach' their robots to use the tool, and they then presented to the class at the end of the session.

Three classes across grades 3 and 4 were chosen randomly for each of these two selected Maker weeks (we worked with a total of two grade 3 classes and two grade 4 classes each year of the program - thus three out of four classes were 
chosen for each Maker unit). As mentioned earlier, a Maker week was four days long. In total therefore, our analysis covered 24 days of science lessons (4 days $\times 6$ Maker weeks - 3 in Year 2 and 3 in Year 3).

In each class, there was an average of 17 students. Across all the 6 classes, there was a total of 102 students, divided into groups of 3 or 4 during the Making activities. With each group being captured by one video camera, this resulted in 40 class lesson videos (one video was on average $41 \mathrm{mins}$ long) that was analyzed. For all the relevant videos, the audio from the recorder was aligned with the video feed from the camera such that background noise could be attenuated.

\section{Data Analysis}

Given the little foundational work on this topic in the Making literature, we decided not to adopt any a priori framework for analysis of the videos. Three coders independently performed an open coding process on the videos of 9 randomly selected students in the sample, focusing on identifying episodes when the students brought into the conversation elements that appeared to make content more relevant to them. The coders took note of these 'relevance' episodes, and met together to compare noted episodes. An agreement was reached as to what consisted of a 'relevance' episode. An episode was defined as consisting of a discourse excerpt (one or more conversational turns). The 40 videos covering 102 students were divided up among 5 coders (the 3 coders with 2 new coders). The 2 new coders were briefed on 'relevance' episodes. Each coder then independently performed an open coding process on their set of videos, reviewing a video multiple times to focus on one student each time. Across all videos, 119 'relevance episodes' were identified. One of the 5 coders reviewed all of the episodes to ensure that they actually identified an aspect of relevance. A sixth coder, who was not part of the five-coder team, then analyzed all of the episodes and established a coding scheme, which was used to code all the episodes.

\section{RESULTS AND FINDINGS}

We were interested in how Making helped to make learning relevant to students when used in elementary science classrooms. Eight different types of relevance were seen. Table 1 shows the types with descriptions and example episodes.

The 'analogy' and 'application of knowledge' types were by far the most prevalent. Figure 5 shows the percentage of the total number of relevance episodes coded that each type addressed. In 'analogy' episodes, students related Making most notably to everyday objects (e.g., car, macaroni, strings, blender), media and cultural items (e.g., Ironman, moonwalking, Minecraft, Lebron James) and their technology experiences (e.g., hotwiring, charging phones). In 'application of knowledge' episodes, the students applied external knowledge from various sources to the Making activity. The external knowledge was from a number of sources: 1) Everyday knowledge (e.g., a robot is typically made of metal); 2) Knowledge from media (e.g., an object seen in a YouTube video); and 3) Other subject matters (e.g., shape is like a polygon).

In 'functionality' episodes, students proposed other possible functions for an aspect of Making, which indicated that they see the usefulness of the particular aspect for other things. 'Preference' episodes were interpreted in two ways: first, relevance in the sense that students bring in elements that they personally like (e.g., a famous person), and second, relevance in the sense that they feel ownership of an aspect of the Making activity as in the example episode given in Table 1. 'Pretend play' episodes were interesting in that the particular student situated an aspect of the Making activity in a fictional context that he or she imagined. These types of episodes were coded as relevance episodes because they suggest that the student would have internalized the Making aspect in a way that they have concocted him- or herself. And finally, 'relation to self' episodes included instances of the students thinking of aspects of the Making activity with respect to themselves or within their own personal situation. In our example episode in Table 1, the student conceptualizes the 3D printer as an electrical appliance and thinks of how many electrical appliances he has at home.

The students drew relationships between various aspects of the Making activity. We identified 6 overarching aspects that triggered relevance. Figure 6 shows the percentage of episodes relating to each Making aspect. Most relationships were drawn based on the product or physical design that resulted from the Making activity (e.g., the mixerhead, the cup robot, the pusher tool). Other relationships were made with the material or individual parts that were used for construction in the Making activity (e.g., Legos, motors), the 3D design that the students made for 3D printing, a process or action inherent to Making (e.g., connecting two wires, gluing, connecting to an Arduino for power), the dynamic motions that result from Making (e.g., cup robot moving across surface, sliding of pusher tool across table), and the resultant sounds in Making (e.g., motor vibration).

\section{DISCUSSION}

RQ1 asked whether students are able to find aspects of relevance during curriculum-aligned Making activities. We identified 119 relevance episodes from tracking 102 students engaging in a curriculum-aligned Making activity that was spread over 4 science lessons (with each lesson being 41 mins on average). This indicates that students do find relevance from the Making activities in the classroom, although the number of relevance episodes was fewer than we initially 
Table 1: Types of relevance during curriculum-aligned Making science lessons

\begin{tabular}{|c|c|c|}
\hline Relevance Type & Description & Example Episode \\
\hline Analogy & $\begin{array}{l}\text { The student compares an aspect of Making } \\
\text { with something from everyday life }\end{array}$ & $\begin{array}{l}\text { Student A presses switch on and off causing motor } \\
\text { to vibrate on the table. } \\
\text { Student B: "Its like a train, it goes beep beep beep!" } \\
\text { Student B motions A to press the switch again. }\end{array}$ \\
\hline $\begin{array}{l}\text { Application of } \\
\text { knowledge }\end{array}$ & $\begin{array}{l}\text { The student brings in some kind of } \\
\text { knowledge pertaining to everyday life into } \\
\text { the Making activity }\end{array}$ & $\begin{array}{l}\text { Adult helper: "Let's see here, you didn't like this? } \\
\text { Student: "These are like the wires and like the nails." } \\
\text { Adult helper: "Oh yeah?" } \\
\text { Student: "Because robots are made out of them, } \\
\text { like metal." }\end{array}$ \\
\hline Functionality & $\begin{array}{l}\text { The student proposes another use for an } \\
\text { aspect of Making other than its intended } \\
\text { use in the Making activity }\end{array}$ & $\begin{array}{l}\text { Student A grabs a 3D-printed mixer head. } \\
\text { Student A: "Hey look a fidget spinner!" } \\
\text { Student B: "Yeah its a fidget spinner" } \\
\text { Student C comes over to look at what } \\
\text { Student A is doing. }\end{array}$ \\
\hline Preference & $\begin{array}{l}\text { The student brings in something that he/she likes } \\
\text { to the Making activity or relates an aspect of the } \\
\text { Making activity to something that he/she likes }\end{array}$ & $\begin{array}{l}\text { Student wires up paper pinwheel to Arduino, } \\
\text { and pinwheel spins without stopping (she } \\
\text { wanted it to stop after a few seconds). } \\
\text { Student: "I'm done babysitting you Sparky. } \\
\text { You are my science experiment. We are scientists." }\end{array}$ \\
\hline Pretend play & $\begin{array}{l}\text { The student imagines a fictional context for an } \\
\text { aspect of Making }\end{array}$ & $\begin{array}{l}\text { Student A hands Student B a large cup robot. } \\
\text { Student B looks around and cannot see the } \\
\text { small cup robot. } \\
\text { Student B: "The baby robot is sleeping in the bed." } \\
\text { Student A: "Baby robot was so scared that he left." }\end{array}$ \\
\hline Relating to self & $\begin{array}{l}\text { The student relates an aspect of Making to self } \\
\text { or a personal situation }\end{array}$ & $\begin{array}{l}\text { Instructor plays a video about 3D printing. } \\
\text { Student A: "We have a lot of electronics in our } \\
\text { house, more than (Student B)" }\end{array}$ \\
\hline
\end{tabular}

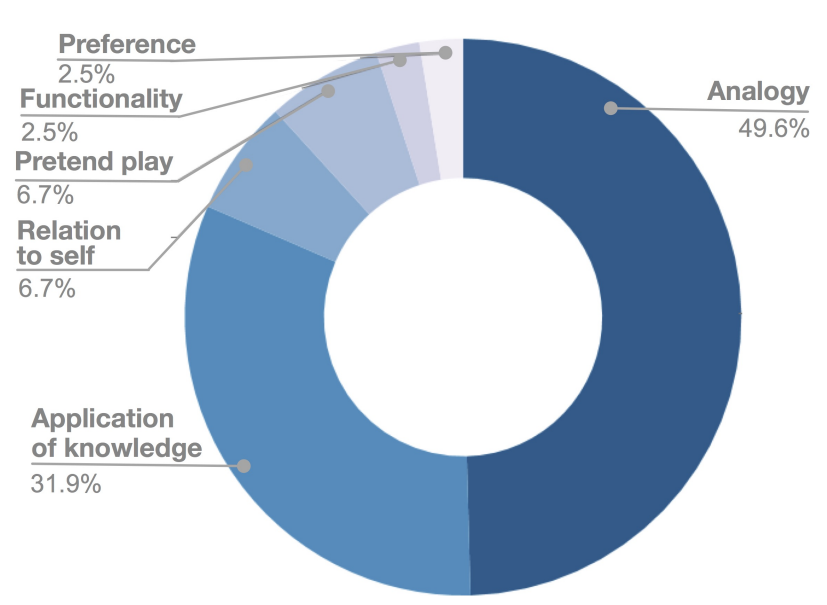

Figure 5: Prevalence of relevance types expected. Certainly, the number of episodes is directly dependent on the exact type of Making activity. Thus, we do expect that in other curriculum-aligned Making activities, students would find it easier or harder to find relevance. However, the simple fact that we found relevance episodes suggest that curriculum-aligned Making is able to make students' learning experience relevant, even though the ultimate objectives of the task do not relate to a personal or community problem like in other conceptualizations of educative Making.

RQ2 asked about the different ways by which students find relevance in curriculum-aligned Making activities. The 6 relevance types that our analysis uncovered reflect a diversity of perspectives of relevance in Making. Some of the types echoed what previous literature has indicated: Bevan's [3] theoretical proposition that Making allows students to bring in cultural resources cuts across all of the relevance 
types. Personal and cultural resources can be seen for instance in students making an analogy with everyday objects during the Making activity. Personal and cultural resources can be seen when students pretend play and create imaginary scenarios for Making products. Most obviously however, personal and cultural resources can be seen in the students' application of knowledge from external sources. The 'application of knowledge' relevance type is also reminiscent of Bevan's [4] 'applying knowledge' indicator of his 'development of understanding' learning dimension, except that his indicator conceptualized the knowledge applied as being mostly knowledge that was gained prior during the lesson or Making activity itself. And the 'preference' and 'functionality' relevance types provide empirical evidence to Somanath's [18] broad characterizations of Making as providing relevance from "likability" and "envisioning future possibilities".

Much of the relevance that the students drew was due to the hands-on nature of the Making activities, i.e., the fact that Making involves tangible artifacts that they can manipulate and engage with. Further, the construction aspect of the Making activities seemed to have contributed significantly to the ability of the students to find relevance since with construction comes the potential for customization and personalization. Relevance benefits from the hands-on nature and construction aspects of Making activities are probably similar to the kinds of benefits that would be obtained from other non-Making-based constructionist learning activities (i.e., those that do not involve Making-related technology). However, other more specific aspects of Making such as the 3D design, processes or actions (e.g., connecting wires, attaching motors), and dynamics and sounds that result from the interactive possibilities that Making technologies enable (e.g., with electronic motors, an artifact can be made to

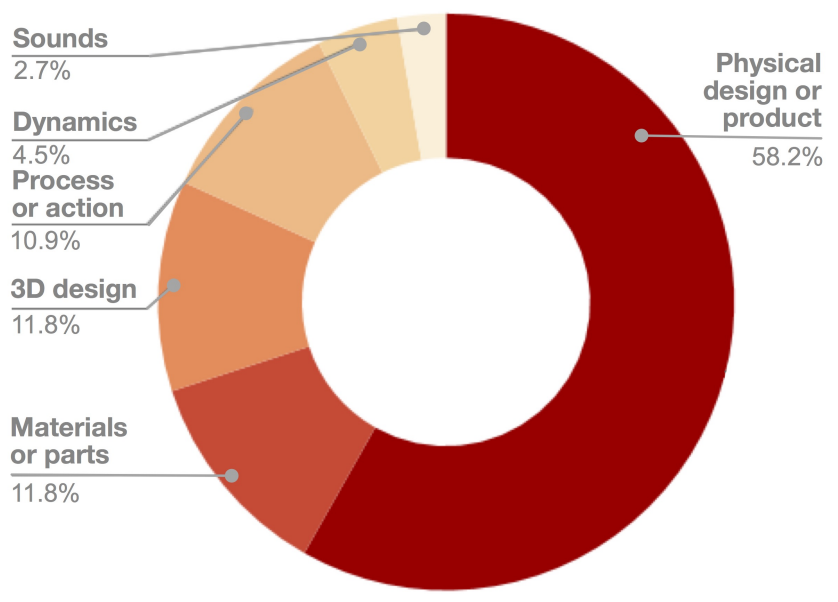

Figure 6: Aspects of Making triggering relevance move in a specific way) helped students to find relevance in the learning activity in interesting ways that other constructionist activities may not necessarily be able to support. This reinforces our proposition that Making enables relevance because of its characteristic as a technologically based enterprise, while school science is typically based on engagement with formal or theoretical models. This does not mean that curriculum-aligned Making dispenses with theoretical knowledge, opting only for the transfer of practical knowledge. We believe that students' engagement with practical knowledge through Making provides a scaffold for the teacher to convey theoretical knowledge.

This paper has presented two main contributions to the area of Making and learning: first, we proposed the idea that a key rationale for integrating Making activities into school curricula is that it may help to make lesson content more relevant for students; and second, from the results of an analysis of a video dataset from a longitudinal Maker program, we presented a taxonomy of how students find relevance in Making activities and the aspects of Making that triggered the relevance.

\section{CONCLUSION}

We presented findings from a qualitative analysis of how a group of elementary students engaged in curriculum-aligned Making in their science classroom found relevance with different aspects of the learning activities. Our results noted that through Making in the science classroom, students were able to make connections between the science and their personal lives, leading to a more personally relevant learning experience. Students found relevance in the activities in six different ways, of which 'analogies' and the 'application of knowledge' were the most common. Our research suggest that Making may be used as a vehicle for teachers to make school science, which is usually more focused on theoretical knowledge, more personally relevant for students.

Our results and conclusions are presented within the context of the following two main limitations: first, we analyzed Making activities that were aligned with only two curriculum units. It is possible that other kinds of Making activities would reveal additional possibilities for other types of relevance; and second, we coded for relevance episodes based only on discourse turns. It is possible that students perceived relevance but did not produce any verbal utterances. Future work will look at how students' self-reported perceived relevance correlate with the degree of relevance episodes that they engage in during curriculum-aligned Making activities in the classroom, as well as applying our taxonomy of relevance episodes to larger datasets. 


\section{ACKNOWLEDGMENTS}

The authors would like to thank all children and teachers who participated in the study, as well as the school administrators who facilitated the logistics. The authors would also like to thank the anonymous referees for their valuable comments and helpful suggestions. The work is supported by the NSF ITEST Grant No. 1433770.

\section{REFERENCES}

[1] Joke Van Aalsvoort. 2004. Activity theory as a tool to address the problem of chemistry's lack of relevance in secondary school chemical education. International fournal of Science Education 26, 13 (2004), 1635-1651.

[2] Tilde Bekker, Saskia Bakker, Iris Douma, Janneke Van Der Poel, and Koen Scheltenaar. 2015. Teaching children digital literacy through design-based learning with digital toolkits in schools. International Journal of Child-Computer Interaction 5 (2015), 29-38.

[3] Bronwyn Bevan. 2017. The promise and the promises of Making in science education. Studies in Science Education 53, 1 (2017), 75-103.

[4] Bronwyn Bevan, Joshua P Gutwill, Mike Petrich, and Karen Wilkinson 2015. Learning through stem-rich tinkering: Findings from a jointly negotiated research project taken up in practice. Science Education 99, 1 (2015), 98-120.

[5] Paulo Blikstein and Dennis Krannich. 2013. The makers' movement and FabLabs in education: experiences, technologies, and research. In Proceedings of the 12th international conference on interaction design and children. ACM, 613-616.

[6] Lisa M Bouillion and Louis M Gomez. 2001. Connecting school and community with science learning: Real world problems and schoolcommunity partnerships as contextual scaffolds. Fournal of research in science teaching 38, 8 (2001), 878-898.

[7] Fernando Cajas. 1999. Public understanding of science: Using technology to enhance school science in everyday life. International fournal of Science Education 21, 7 (1999), 765-773.

[8] Sharon Lynn Chu, Rebecca Schlegel, Francis Quek, Andrew Christy, and Kaiyuan Chen. 2017. 'I Make, Therefore I Am': The Effects of Curriculum-Aligned Making on Children's Self-Identity. In Proceedings of the 2017 CHI Conference on Human Factors in Computing Systems. ACM, 109-120.

[9] Edward P Clapp, Jessica Ross, Jennifer O Ryan, and Shari Tishman. 2016. Maker-centered learning: Empowering young people to shape their worlds. John Wiley \& Sons.

[10] Jonathan Cohen, W Monty Jones, Shaunna Smith, and Brendan Calandra. 2017. Makification: Towards a framework for leveraging the maker movement in formal education. Fournal of Educational Multimedia and Hypermedia 26, 3 (2017), 217-229.

[11] Nomusa Dlodlo and Ronald Noel Beyers. 2009. Experiences of South African high school girls in a fab lab environment. (2009).

[12] Deborah A Fields and Whitney L King. 2014. So, I think I'm a programmer now. Developing connected learning for adults in a university craft technologies course. In Learning and Becoming in Practice: The International Conference of the Learning Sciences (ICLS), Vol. 1. 927-936.

[13] Erica Rosenfeld Halverson and Kimberly Sheridan. 2014. The maker movement in education. Harvard Educational Review 84, 4 (2014), 495-504.

[14] Ralf Marks, Marc Stuckey, Nadja Belova, and Ingo Eilks. 2014. The Societal Dimension in German Science Education-From Tradition towards Selected Cases and Recent Developments. Eurasia fournal of Mathematics, Science \& Technology Education 10, 4 (2014).
[15] Kathryn Mayoh and Stephen Knutton. 1997. Using out-of-school experience in science lessons: reality or rhetoric? International fournal of Science Education 19, 7 (1997), 849-867.

[16] Kylie Peppler. 2013. STEAM-powered computing education: Using e-textiles to integrate the arts and STEM. Computers Education (2013), 1.

[17] Rachel Charlotte Smith, Ole Sejer Iversen, and Mikkel Hjorth. 2015. Design thinking for digital fabrication in education. International fournal of Child-Computer Interaction 5 (2015), 20-28.

[18] Sowmya Somanath, Laura Morrison, Janette Hughes, Ehud Sharlin, and Mario Costa Sousa. 2016. Engaging'At-Risk'Students through Maker Culture Activities. In Proceedings of the TEI'16: Tenth International Conference on Tangible, Embedded, and Embodied Interaction. ACM, 150-158.

[19] Marc Stuckey, Peter Heering, Rachel Mamlok-Naaman, Avi Hofstein, and Ingo Eilks. 2015. The philosophical works of Ludwik Fleck and their potential meaning for teaching and learning science. Science \& Education 24, 3 (2015), 281-298.

[20] MA Togou, C Lorenzo, E Lorenzo, G Cornetta, and GM Muntean. 2018. Raising Students' Interest in STEM Education via Remote Digital Fabrication: An Irish Primary School Case Study. In EDULEARN Conference.

[21] Shirin Vossoughi and Bronwyn Bevan. 2014. Making and tinkering: A review of the literature. National Research Council Committee on Out of School Time STEM (2014), 1-55. 